\title{
Suicidal ideation and attempt among South African medical students
}

\author{
L van Niekerk, L Scribante, P J Raubenheimer
}

International data reveal that medical students are at higher risk of attempting suicide than the general population. We aimed to determine the prevalence of suicidal ideation and attempt among South African medical students from three universities and identify key predisposing risk factors. Data were collected via a questionnaire to medical students on demographics, mental health history, depressive symptoms, suicidal ideation and attempt. A total of 874 medical students from three universities were enrolled. We found a high prevalence of suicidal ideation $(32.3 \%)$ and suicidal attempt $(6.9 \%)$, which is three times higher than the general age-appropriate South African population. Simple screening questionnaires can identify such students, enabling universities to provide targeted and improved support for at-risk students.

S Afr Med J 2012;102(6):372-373
Nearly one million people die annually as a result of suicide, putting it among the top three leading causes of death in men and women aged 15 - 44 years. ${ }^{1}$ The rate of suicide in sub-Saharan Africa (32/100 000) is the second-highest worldwide. The South African Stress and Health Study of 2002 - 2003 found the incidence of suicidal attempt to be $1.8 \%$ in men and $3.8 \%$ in women. ${ }^{2}$ South Africans aged 18 - 34 years had the highest rate of completed suicide. ${ }^{2}$

Age is not the sole predisposing factor for suicide. Internationally, doctors and medical students are at additional risk. The rate of suicide in the USA was $40 \%$ and $130 \%$ higher among male and female physicians, respectively, than the general population. ${ }^{3}$ In the USA and Norway, suicidal ideation was higher in medical students than the general population. ${ }^{4,5}$ Suicidal ideation had a strong correlation with personal and professional distress. ${ }^{4}$

A study among medical students at the University of Pretoria found that $8.1 \%$ of students 'sometimes' or 'often' considered suicide, and $5.1 \%$ had made a suicidal attempt. Although higher than national statistics for age-related counterparts, these rates were similar to those for students enrolled in non-medical degrees at the university. ${ }^{6}$ This is the first study on a larger national sample of medical students from three universities in South Africa that assessed the prevalence of suicidal ideation and attempt, and possible risk factors for suicide.

\section{Methods}

Medical students from the University of Pretoria (UP), the University of Cape Town (UCT) and the University of the Free State (UFS) were invited to participate in an anonymous and voluntary questionnaire. A convenience sample was used. Questionnaires were distributed to students in the pre-clinical (years 1 - 3 of study) and the clinical years (years 4 and 5). Final-year students were not included owing to logistical difficulties.

Department of Medicine, University of Cape Town

L van Niekerk, MB ChB, MSc Public Health

Department of Psychiatry, University of Pretoria

L Scribante, MB ChB, MFamMed, FCPsych (Cert Child Psychiatry)

Department of Medicine, University of Cape Town

P J Raubenheimer, MB BCh, FCP (SA)
A specifically designed questionnaire collected demographic characteristics: age, gender, year of study and relationship status. Secondly, questions assessed the incidence of prior mental health disorder diagnosis: 'Have you ever been diagnosed with depression?', 'Have you ever been diagnosed with any other psychiatric disorder?', and 'Have you ever used any mood-enhancing medication?' Questions regarding symptoms of depression and burnout were included: 'Do you feel more tired than you used to?', 'Do you feel you get as much satisfaction out of things as you used to?' and 'Do you feel positive about your future?' Thirdly, questions were asked surrounding suicidal ideation, from the standardised Paykel's instrument, which has been used to assess suicidal ideation and attempt in the general population as well as in medical professionals: ' Have you ever felt your life is not worth living?', 'Have you ever thought about taking your own life?', and 'Have you ever made an attempt on your own life?'. Other questions concerned respondents' feelings towards medicine as a career choice and awareness of support services at their university and their willingness to use the known support structures.

SAS version 8.2 statistical package analysed the data, with bivariate chi-squared tests or Fisher's exact test used as appropriate to test for associations between individual variables. The study was approved by the Ethics Review Board of the University of Pretoria, and permission was granted from each institution to collect the data.

\section{Results}

A total of 874 medical students completed the survey. Most were in their 2nd and 3rd years and $<25$ years of age; $63 \%$ were female and $58 \%$ were in a current relationship. Overall, $11.9 \%$ of all students had a previous diagnosis of depression and $4.7 \%$ of another psychiatric diagnosis. Mood-enhancing medication had been used by $15.8 \%$. A total of $37.5 \%$ of students answered that their 'Life is not worth living' and $32.3 \%$ reported suicidal ideation. The overall prevalence of suicidal attempt among medical students at the three universities was $6.2 \%$. There were no significant differences between universities.

Table 1 shows the characteristics of students who attempted suicide compared with those who had not. There was no evidence of an association between suicide attempt and sex, age, relationship status, or place or year of study. There was strong evidence of an association between suicidal attempt and suicidal ideation, previous diagnosis of depression or other psychiatric condition, and use of mood-enhancing medication, and with symptoms suggestive of depression or burnout. There was a high degree of dissatisfaction with career choice; $55 \%$ reported that they considered studying a different degree, and 35\% that their career choice was incorrect and uninformed. 
Table 1. Characteristics of students never attempting suicide v. students attempting suicide

\begin{tabular}{|c|c|c|c|c|c|}
\hline & \multicolumn{2}{|c|}{$\begin{array}{l}\text { Not attempted } \\
\text { suicide }\end{array}$} & \multicolumn{2}{|c|}{ Attempted suicide } & \multirow[b]{2}{*}{$p$-value ${ }^{*}$} \\
\hline & $n$ & $\%$ & $n$ & $\%$ & \\
\hline \multicolumn{6}{|l|}{ Demographics } \\
\hline Gender & & & & & 0.804 \\
\hline Male & 299 & 36.9 & 19 & 35.2 & \\
\hline Female & 512 & 63.1 & 35 & 64.8 & \\
\hline Age & & & & & 0.076 \\
\hline$<25$ & 763 & 94.1 & 47 & 87.0 & \\
\hline$>25$ & 49 & 5.9 & 7 & 13.0 & \\
\hline Relationship & & & & & 0.880 \\
\hline Single & 463 & 57.1 & 30 & 55.6 & \\
\hline In relationship & 340 & 42.9 & 23 & 44.4 & \\
\hline Year of study & & & & & 0.382 \\
\hline Pre-clinical & 656 & 80.9 & 41 & 75.9 & \\
\hline Clinical & 156 & 19.1 & 13 & 24.1 & \\
\hline \multicolumn{6}{|l|}{ Prior psychiatric history } \\
\hline Diagnosed depression & 75 & 9.2 & 27 & 50 & $<0.001$ \\
\hline Diagnosed other psychiatric condition & 28 & 3.5 & 13 & 24 & $<0.001$ \\
\hline Use of mood-enhancing medication & 114 & 14 & 24 & 44 & $<0.001$ \\
\hline \multicolumn{6}{|l|}{ Symptoms of burnout/depression } \\
\hline More tired than usual & 754 & 93 & 49 & 91 & 0.429 \\
\hline Less satisfaction from life than usual & 68 & 8 & 13 & 24 & $<0.001$ \\
\hline Never feel positive about the future & 10 & 1.2 & 11 & 20 & $<0.001$ \\
\hline \multicolumn{6}{|l|}{ Suicidal ideation } \\
\hline Life not worth living & 279 & 34.4 & 48 & 91 & $<0.001$ \\
\hline Thought about taking own life & 234 & 28.9 & 45 & 84.9 & $<0.001$ \\
\hline
\end{tabular}

The Health Professions Council of South Africa (HPCSA) identifies impairment in undergraduate medical students as functioning below expectations and manifesting personal, interperson or work-related difficulties. Impairment includes physical and mental conditions. The HPCSA's 1996 National Strategy on Impaired Providers emphasises early identification of impaired students and encourages preventive measures by training institutions. 'Training institutions should become concerned about student needs in relation to workload, relaxation, social adaptation, personal and financial matters as well as provide adequate counselling.? We did not assess whether suicidal ideation or attempt correlates with poor work performance; however, the high prevalence should encourage medical schools to improve identification of students at risk and institute more effective support structures. A simple annual questionnaire at enrolment and seeking to identify suicidal thought, symptoms of depression and burn-out and previous psychiatric history could assist in identifying students who may need support or intervention.

Limitations of our study include that not all South African universities providing medical training were included, which could limit the generalisability. Nevertheless, no significant differences were found

Although student support structures were available at all universities, awareness of these varied greatly. Overall, $45.6 \%$ of students were aware of a support system at their university (67\%, $43 \%, 29.8 \%$ at UCT, UP and UFS respectively). Of those aware of a support system, only $28.3 \%$ could name this structure. A fifth of students reported that they had made use of such support structures, and $72.3 \%$ would be willing to make use of them.

\section{Discussion}

Ours is believed to be the first national study assessing suicidal risk of South African medical students. Almost a third of medical students reported suicidal ideation, which is three times higher than comparative data worldwide. ${ }^{4}$ Of most concern was the finding of a $6.2 \%$ prevalence of suicidal attempt among medical students, against a national prevalence of $2.95 \%$ in this age group. ${ }^{1}$

Several risk factors for suicidal attempt were found. Suicidal ideation had a strong association with suicidal attempt, and its importance is emphasised by the finding that $50 \%$ of planned attempts occur within one year of suicidal ideation. ${ }^{2}$ Further risk factors were a previous diagnosis of depression or psychiatric disorders, use of moodenhancing medication, and symptoms of decreased life satisfaction and burnout. As timing of suicidal ideation and attempt was not established, we cannot be sure that medical school contributes to, as opposed to medical school admission criteria selecting for, suicidal trainees; both possibilities should be considered. between the three universities studied. As in other such surveys, response rates were low, and response bias cannot be excluded. Participation was voluntary, and students experiencing severe suicidal symptoms or distress might have opted out of the survey, although that would lead to a lower than actual prevalence reported. Alternatively, students to whom the topic is not relevant might be less likely to participate. As timing of suicidal ideation and attempt was not established, we cannot be sure that medical school contributes to, as opposed to medical school admission criteria selecting for, suicidal trainees.

\section{References}

1. WHO. World Health Report 2003- Shaping the Future. Geneva: World Health Organization. http:// www.who.int/whr/2003/en/ (accessed 14 November 2011)

Joe S, Stein DJ, Seedat S. Non fatal suicide behaviour among South Africans. Social Psychiatry \& Psychiatric Epidemiology 2008;43:454-461.

Schernhammer E. Taking their own lives - The high rate of physician suicide. N Engl J Med 2005:325:24.

Dyrbye LN, Thomas MR, Massie FS. Burnout and suicidal ideation among U.S. medical students. Ann Intern Med 2008;149(5):334-341.

Intern Med 2008;149(5):334-341.
5. Tyssen R, Vaglum P, Gronvold NT. Suicidal ideation among medical students and young physicians: a 5. Tyssen R, Vaglum P, Gronvold NT. Suicidal ideation among medical students and young physic
nationwide and prospective study of prevalence and predictors. J Affect Disord 2001;64:69-79.

Van Niekerk L, Viljoen AJ, Rischbieter P, Scribante L. Subjective experience of depressed mood amongs medical students at the University of Pretoria. South African Journal of Psychiatry 2008;14(1):27-31. HPCSA. A National Strategy for Managing Impairment in Students and Practitioners Registered with the Council. 1996. http://www.hpcsa.co.za/fitness_practice.php (accessed 1 December 2011). 